\title{
Fake News Científicas: Percepção, Persuasão e Letramento
}

\author{
Scientific Fake News: Perception, Persuasion and Literacy
}

Sheila Freitas Gomes ${ }^{1}$

Juliana Coelho Braga de Oliveira Penna'

Agnaldo Arroio ${ }^{1}$

'Universidade de São Paulo (USP), Faculdade de Educação, São Paulo, SP, Brasil. Autora correspondente: sheilafg@usp.br

Resumo: A linha tênue que separa o fato da ficção está cada vez mais dissimulada, criando realidades paralelas que turvam a visão da sociedade. $\mathrm{O}$ atual ensaio sobre cegueira saramaguiana reapresenta-se com o auxílio da velocidade de um simples toque na tela nas mídias sociais. Nesse sentido, o presente artigo explora a compreensão de quais elementos influenciam na credibilidade das fake news científicas. Os principais conceitos para elucidar essa questão são a percepção e a persuasão. O estudo é de natureza qualitativa e contou com a participação de 232 sujeitos por intermédio de um questionário on-line. Os resultados obtidos demonstram que a renda familiar, a escolaridade e a articulação do discurso persuasivo são elementos essenciais para a credibilidade das fake news.

Palavras-chave: Fake news; Mídias sociais; Divulgação científica; Educação científica.

\begin{abstract}
The fine line separating fact from fiction is increasingly hidden, creating parallel realities that cloud the view of society. The current essay on saramaguian blindness is reintroduced with the aid of the speed of a simple touch on the screen in social media. In this sense, the present article explores the comprehension of which elements influence the credibility of scientific fake news. The main concepts to elucidate this question are perception and persuasion. The study is qualitative in nature, with the participation of 232 subjects through an online questionnaire. The results show that family income, schooling, and the articulation of persuasive discourse are essential elements for the credibility of fake news.

Keywords: Fake news; Social media; Science dissemination; Science education.
\end{abstract}




\section{Introdução}

Realidades falsas criarão humanos falsos. Ou, os humanos falsos irão gerar realidades falsas e depois vendê-las a outros humanos, transformando-as, eventualmente, em falsificações de si mesmos. Então acabamos com humanos falsos inventando realidades falsas e depois vendendo para outros humanos falsos.

Philip K. Dick (1996).

Pensar sobre a divulgação científica é uma ação de constante renovação por compreender "[...] utilização de recursos, técnicas, processos e produtos (veículos ou canais) para a veiculação de informações científicas, tecnológicas ou associadas a inovações ao público leigo" (BUENO, 2009, p. 162). É inegável a sua relevância para a circulação de informações sobre as ciências na sociedade, de modo que as pessoas possam se apropriar desses saberes participando de maneira ativa desse processo culturalmente dinâmico (VOGT, 2006, p. 3).

Notícias envolvendo temas sobre ciência e tecnologia encontram-se presentes em variados espaços. O trabalho de divulgação não se restringe apenas a artigos científicos: ele pode ser realizado em programas de televisão, revistas, jornais e, mais recentemente, em redes sociais, mas será que tudo aquilo que circula nesses meios está pautado em uma literatura científica de fato?

$\mathrm{Na}$ atual conjuntura, a circulação de discursos não é de exclusividade da mídia jornalística ou dos meios oficiais de divulgação científica. Hoje, os próprios usuários das redes sociais 'curtem' as mais diversas informações e compartilham-nas com os mais diversos públicos. Essa talvez fosse uma grande oportunidade de democratização da informação, entretanto esse território virtual se manifesta repleto de disputas discursivas entre o real e a ficção.

Nesse contexto, o presente artigo objetiva compreender os motivos que contribuem para a divulgação de fake news. A pergunta norteadora de pesquisa é: quais são os elementos que endossam a credibilidade das fake news científicas? O estudo justifica-se no entendimento de que a forte difusão de informações por meio de mídias sociais pode influenciar na tomada de grandes decisões em sociedade.

Trata-se de estudo de natureza qualitativa e exploratória, composto por 232 sujeitos de um grupo bem estratificado. Os dados foram coletados por meio de um questionário online, elaborado e validado pelos autores, composto por 28 questões. A coleta de dados foi realizada entre os meses de novembro e dezembro de 2018 com sujeitos que moram nos estados de São Paulo e Rio de Janeiro. A análise dos dados foi feita por meio da escala phrase completion (HODGE; GILLESPIE, 2007).

\section{A Era da Desinformação: Percepção, Persuasão e Fake News}

No ano de 2016, o Oxford Dictionary elegeu pós-verdade como a palavra do ano. Naquele contexto, haviam ocorrido dois eventos emblemáticos: a saída do Reino Unido da União Europeia e a vitória de Donald Trump para a presidência dos Estados Unidos. Além de compartilhar o mesmo ano, os dois eventos tiveram em comum um alto índice de disseminação de notícias falsas ou, em inglês, fake news, principalmente por meio das mídias sociais. Por esse motivo, a palavra pós-verdade destacou-se naquele ano, definida como "o 
que se relaciona ou denota circunstâncias nas quais fatos objetivos têm menos influência em moldar a opinião pública do que apelos à emoção e a crenças pessoais" (OXFORD..., 2016, tradução nossa).

As emoções e as crenças pessoais têm grande impacto na formação da percepção que o indivíduo tem do mundo à sua volta. A percepção trata-se da "organização e interpretação de informações sensoriais conscientemente" (MYERS; DEWALL, 2017, p. 173), portanto não há uma única forma de percepção, uma vez que há variados modos de interpretação e de relação com o repertório individual de informações ou conhecimentos que cada pessoa possui.

Todavia, a percepção pode estar ou não alinhada aos fatos. Quando não alinhada, são criadas realidades alternativas "que não se baseiam em fatos, mas em emoções. Realidades alternativas que se baseiam na percepção, não em dados" (MEDRÁN, 2017, p. 33). Dessa maneira, viabiliza-se uma distorção dos acontecimentos reais.

Um exemplo sobre como a percepção pode estar equivocada é a hipótese da terceira pessoa, segundo a qual o sujeito não se percebe prejudicado por influências externas, contudo interpreta que os outros, sim, podem ser influenciados (DAVISON, 1983). Em outras palavras, é superestimado o efeito negativo sobre as outras pessoas, e é subestimado o efeito negativo sobre si.

Nesse sentido, a percepção do que é ou não verídico pode ser manipulada recorrendo, por exemplo, às emoções e crenças pessoais, 'cegando' a percepção dos fatos - ou melhor, conduzindo ao mundo da pós-verdade.

Entretanto, é importante ponderar que a pós-verdade não diz respeito à superação de um momento em que houve somente a verdade pura e objetiva, muito pelo contrário: esse momento nunca chegou. As notícias falsas sempre estiveram e estarão por aí, a questão central é o impulso cada vez mais veloz que elas têm ganhado (GENESINI, 2018).

A velocidade está sendo a grande 'carta na manga' das notícias falsas, as quais se disseminam por meio de diversas mídias sociais como WhatsApp, Facebook, Twitter, entre outras de grande aderência. A notícia ganha impulso, propaga-se como um verdadeiro incêndio virtual e, dessa forma, consolida opiniões e supostos conhecimentos sobre os mais variados temas. Por exemplo, na área da saúde: preocupado com a repercussão das notícias fictícias, o Ministério da Saúde, no ano de 2018, criou um canal chamado "saúde sem fake news", no qual é disponibilizado um número de telefone para que as pessoas, antes de compartilhar, possam enviar as supostas notícias verdadeiras e verificá-las.

Outro fator que favorece a credibilidade das fake news foi pensado por volta do ano 350 a.C. É a persuasão, descrita por Aristóteles como sendo dependente de três variáveis: logos, pathos e ethos. O logos refere-se ao modo lógico no qual o orador se expressa pelo discurso. O pathos é relativo à forma com a qual o orador invoca as emoções do seu público. E o ethos é a maneira com a qual o orador se apresenta como figura competente (GOUVÊA, 2017). Ou seja, para que uma inverdade possa tomar contornos de uma possível verdade, há um apelo por intermédio do discurso da racionalidade e das emoções. Um exemplo de como pode se configurar uma notícia falsa, de acordo com as variáveis aristotélicas, está presente na transcrição do áudio de uma notícia falsa sobre a vacina da febre amarela (Figura 1). 
Figura 1 - A estrutura persuasiva de fake news compartilhada em 2017

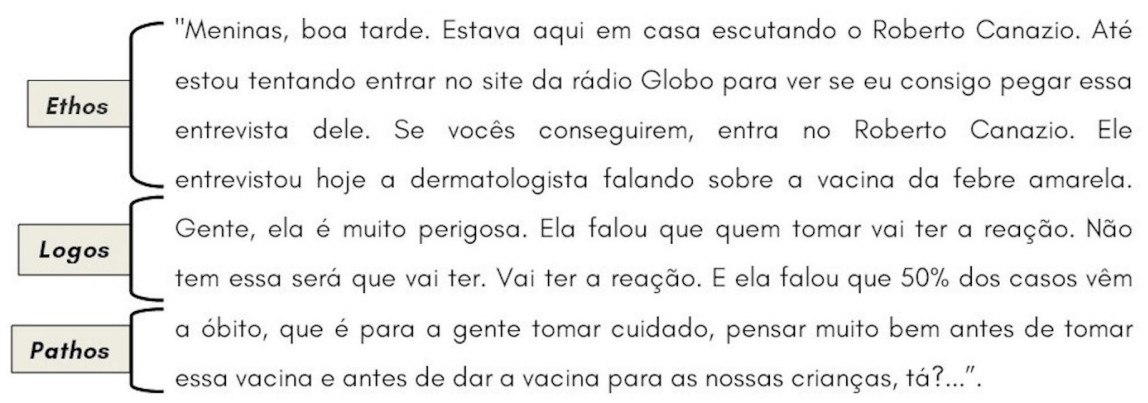

Fonte: elaborado pelos autores.

Na transcrição acima, o ethos é evocado tanto pela figura do apresentador de uma rádio conhecida quanto pela figura de uma dermatologista. No segundo, momento o logos é apresentado pela utilização de um dado numérico e de jargões empregados na área da saúde, expressando racionalidade, lógica. Por fim, o pathos aparece ao mencionar-se que tal vacina poderia levar crianças e adultos a óbito.

Dessa forma, a notícia falsa acaba por persuadir e influenciar o maior número de pessoas. Somando-se a isso a alta velocidade de compartilhamento, as consequências podem ser das mais preocupantes, como: ainda na área da saúde, o possível reaparecimento de doenças erradicadas; no cenário político, eleições baseadas em ficção, sendo uma ameaça à sociedade e à democracia.

Desse modo, faz-se necessário pensar em alternativas que possam promover uma perspectiva mais cidadã e menos alienada sobre a realidade.

\section{O Letramento Midiático e o Informacional: uma jornada para a cidadania}

Construir uma formação cidadã implica despertar no sujeito autonomia para tecer seus próprios pontos de vista de forma crítica sobre a realidade. Não se trata de viver de modo passivo, consumindo tudo o que lhe é oferecido de maneira ingênua, mas sim de ter voz e fazer-se ouvir nessa trama discursiva.

Dois conceitos pertinentes são o letramento midiático e o informacional. O letramento diz respeito ao domínio não só da leitura e da escrita, ou seja, a alfabetização, como também da compreensão de ser sujeito no interior das práticas sociais (SOARES, 1998). Nos documentos da UNESCO aparece o termo em inglês media and information literacy, no qual a palavra literacy costuma ser associada à alfabetização. Segundo Cunha (2017, p. 171), “[...] a expressão 'letramento' só foi dicionarizada recentemente e ainda não é muito difundida fora do campo acadêmico específico que estuda o ensino de língua, não é de admirar que literacy seja, na maioria das vezes, associado à 'alfabetização'". Sendo assim, será utilizado o conceito de letramento em vez do de alfabetização por entender-se que é o termo que mais se aproxima do conceito da UNESCO.

Nesse contexto, o letramento informacional refere-se a:

1- definição e articulação de necessidades informacionais; 2- localização e acesso a informação; 3- organização da informação; 4- uso ético da informação; 5- comunicação da informação; 6 - uso das habilidades de TICs no processamento da informação (WILSON et al., 2013, p. 18). 
Enquanto o letramento midiático é relativo a:

1- compreensão do papel e das funções das mídias em sociedades democráticas; 2compreensão das condições sob as quais as mídias podem cumprir essas funções; 3avaliação crítica do conteúdo midiático à luz das funções da mídia; 4- compromisso junto às mídias para a autoexpressão e a participação democrática; 5- revisão das habilidades (incluindo as TICs) necessárias para a produção de conteúdo pelos usuários (WILSON et al., 2013, p. 18).

De acordo com Arroio (2017), os letramentos midiático e informacional podem viabilizar a formação cidadã na perspectiva de direito humano fundamental, por meio do qual o sujeito consegue se comunicar, transmitindo e recebendo informações de maneira autônoma e criteriosa, correspondendo de forma ativa ao presente contexto da comunicação. Tais letramentos podem, assim, viabilizar a interlocução do sujeito com a sociedade de modo que ele possa se relacionar de maneira mais consciente com a mídia e por meio dela.

Os letramentos midiático e informacional fazem-se necessários, sobretudo, na perspectiva de um ensino de ciências mais contextualizado com as novas demandas para uma leitura de mundo mais consciente, tendo em vista a problematização dos discursos científicos concebidos como neutros e tomados como verdades absolutas quando, na verdade, são feitos por humanos e servem a interesses (CACHAPUZ et al., 2005). Portanto, ensinar ciências é "ensinar a ler sua linguagem, compreendendo sua estrutura sintática e discursiva, o significado de seu vocabulário, interpretando suas fórmulas, esquemas, gráficos, diagramas, tabelas etc." (SANTOS, 2007, p. 484).

A articulação dos letramentos midiático e informacional com o letramento científico potencializa nos cidadãos uma visão mais autônoma e crítica da realidade. É importante considerar que, em uma sociedade democrática,

[...] as pessoas idealmente exercem grande poder sobre as decisões e políticas que o governo faz. Não é difícil ver que uma população cientificamente analfabeta falhará miseravelmente em encorajar seus legisladores a tomar decisões informadas sobre questões científicas, sejam elas algo tão pequeno quanto proteger um córrego local ou algo em escala global, como o aumento do nível do mar ou investigação sobre células-tronco (KANODE, 2015, p. 8, tradução nossa).

Tanto o letramento científico como o midiático e o informacional podem vir a despertar a capacidade de discernir os vieses contidos nos discursos veiculados na mídia, capacitando as pessoas a uma visão menos conformista sobre assuntos de interesse individual e coletivo em âmbito local e global.

\section{Metodologia}

A pesquisa tem natureza qualitativa (LÜDKE; ANDRÉ, 2007) devido ao entendimento de que a realidade é constituída de vieses que são interpretados dentro de um contexto social, distanciando-se da testagem de hipóteses que visam uma realidade estritamente objetiva, independente e consequentemente mensurável, de acordo com uma perspectiva positivista. 
Quanto aos fins, trata-se de uma pesquisa exploratória, pois visa compreender quais são os elementos que influenciam na credibilidade das fake news científicas. Quanto aos meios, é uma pesquisa bibliográfica, pois utiliza livros, artigos, teses, dissertações etc. para elucidar o problema de pesquisa.

$O$ instrumento de coleta de dados foi um questionário on-line da plataforma SurveyMonkey ${ }^{\oplus}$, elaborado e validado pelos autores, constituído de 28 questões ( 27 fechadas e 1 aberta). A coleta de dados foi realizada entre os meses de novembro e dezembro de 2018 com sujeitos que moram nos estados de São Paulo e Rio de Janeiro. O questionário possuía quatro notícias falsas e apenas uma verdadeira para que os participantes pudessem responder perguntas quanto à veracidade, à motivação de compartilhamento e a como outra pessoa poderia julgar aquela notícia.

As respostas relativas às notícias foram construídas em uma escala de 0 a 10 seguindo o modelo phrase completion, criado por Hodge e Gillespie (2007). Nessa escala, as respostas são subdivididas em três categorias, que, nesta pesquisa, foram assumidas como: falso, dúvida e verdadeiro (Figura 2). Dessa forma, os participantes poderiam expor o nível de credibilidade nas notícias.

Figura 2 - Escala phrase completion

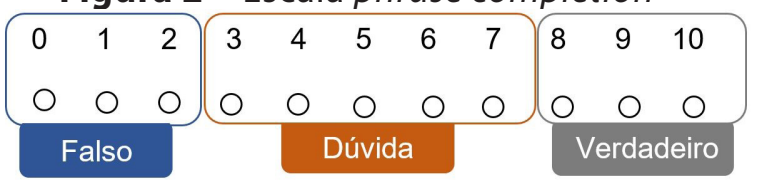

Fonte: elaborado pelos autores.

Participaram deste estudo 232 sujeitos, compondo um grupo heterogêneo com diferentes idades, profissões, níveis de escolaridade, entre outros, de modo a ter uma amostra representativa e o mais fidedigna possível.

O procedimento de análise de dados ocorreu por meio da interpretação das respostas sobre os seguintes aspectos: (1) a frequência de uso das mídias sociais; (2) o nível de confiabilidade nas mídias sociais; (3) a motivação de compartilhamento das fake news; (4) o efeito das fake news sobre outra pessoa; (5) a relação entre escolaridade e credibilidade em fake news; (6) a relação entre renda familiar e crença em fake news; (7) o critério de embasamento para julgar a notícia como verídica; e, (8) a comparação entre uma notícia falsa e uma verdadeira compartilhadas por WhatsApp.

\section{Resultados e Discussões}

Sobre o consumo das mídias sociais, os participantes da pesquisa foram questionados a respeito da frequência de uso de plataformas digitais - Facebook, Instagram, YouTube, Twitter e WhatsApp. As respostas apresentavam cinco categorias viáveis: não utilizo, utilizo pouco, utilizo regularmente, utilizo muito e utilizo sempre.

Dentre as mídias sociais destaca-se o WhatsApp como a de maior consumo, seguido por Facebook, Instagram e YouTube, sendo o Twitter identificado como o menos utilizado pelos participantes (Figura 3). 
Figura 3 - Frequência de consumo das mídias sociais

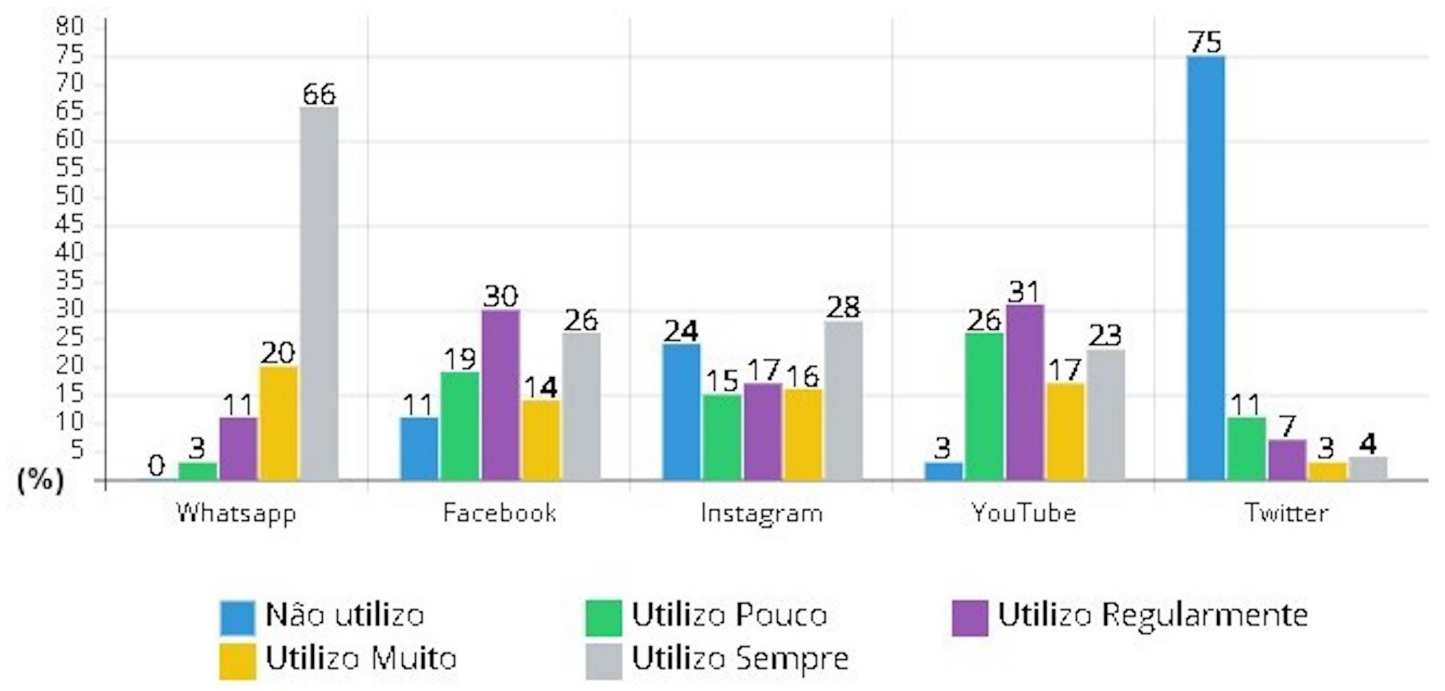

Fonte: elaborado pelos autores.

Na sequência, foram indagados a respeito da veracidade de quatro fake news veiculadas a quatro diferentes mídias sociais. A notícia do Blog, que relatava a morte de 37 milhões de abelhas causada pelo plantio de milho geneticamente modificado, exibiu o maior índice de dúvida (45\%), seguido daqueles que afirmaram ser uma notícia falsa (35\%) e, por fim, aqueles que afirmavam ser uma notícia verdadeira (23\%). Dentre as fake news apresentadas, as veiculadas no Blog e no Twitter apresentaram maior taxa de credibilidade (Figura 4).

A notícia compartilhada no Twitter tratava de uma suposta máquina que fazia separação de bolinhas coloridas por física quântica. A notícia foi considerada falsa (40\%), mas houve aqueles que ficaram em dúvida (37\%) e que afirmaram ser verdadeira (23\%).

A notícia compartilhada pelo WhatsApp versava sobre uma suposta maculopatia, descrita como câncer nos olhos, causada pelo uso excessivo de aparelhos celulares no escuro. A maioria dos participantes afirmou tratar-se de uma notícia falsa (53\%), mas também houve os que ficaram em dúvida (35\%) e ainda aqueles que afirmaram ser uma notícia verdadeira (14\%).

A notícia do Facebook referia-se a uma barata que, quando tocada, supostamente infectaria a pessoa com um vírus capaz de produzir furos pelo corpo. A notícia foi considerada falsa (82\%), houve aqueles que ficaram em dúvida (11\%) e os que a julgaram verdadeira (7\%).

É importante ponderar que as maiores porcentagens de credibilidade na notícia concentraram-se naquelas que melhor articularam ethos e logos. O uso, por exemplo, de jargões científicos como 'geneticamente modificado', 'física quântica' e 'maculopatia' demonstrou legitimidade racional no discurso persuasivo, ou seja, logos. A atribuição de uma figura competente no caso, como um pesquisador, conduziu ao ethos. As fake news que mais tiveram ênfase em pathos não obtiveram muito crédito, como as veiculadas no WhatsApp e no Facebook em especial esta última, que apresentou principalmente pathos. 
Figura 4 - Fake news compartilhadas em quatro mídias sociais

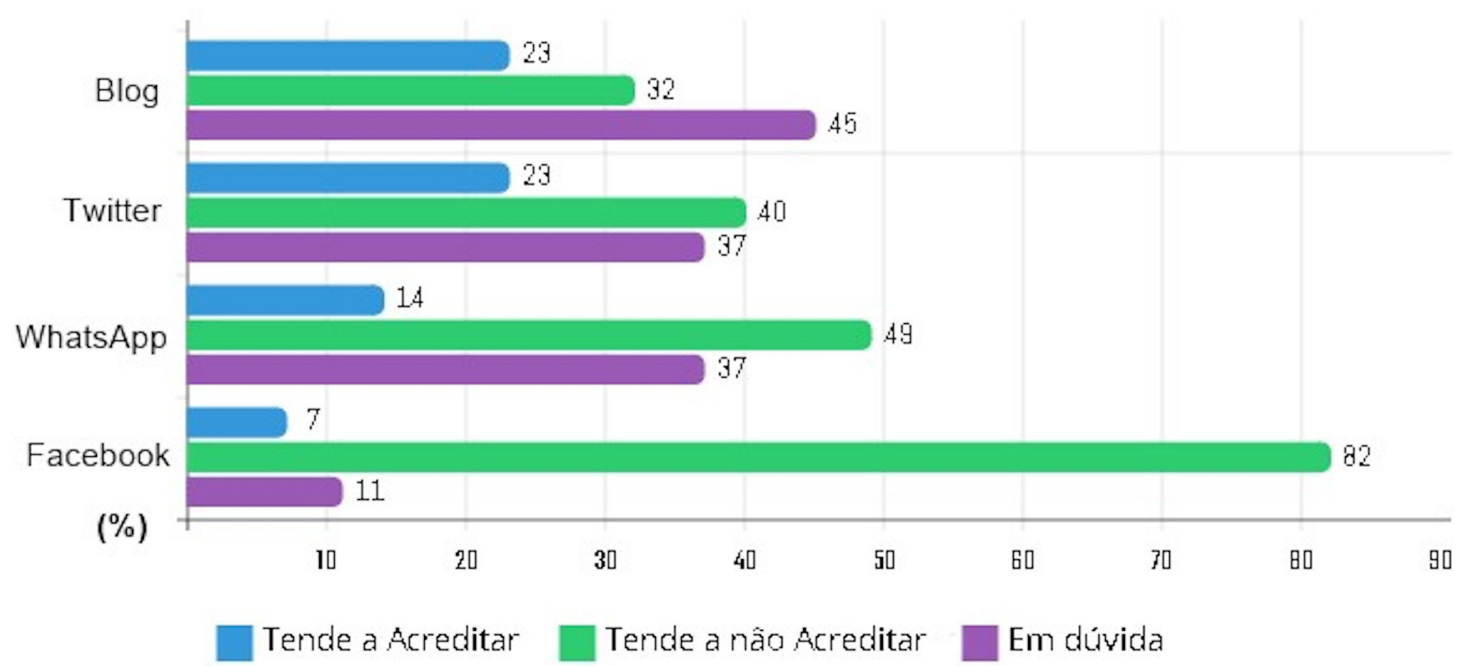

Fonte: elaborado pelos autores.

Posteriormente, perguntou-se aos participantes se eles se sentiam motivados a compartilhar as notícias apresentadas. A maioria expressou-se de forma contrária a essa motivação - Facebook (83\%), WhatsApp (68\%), Twitter (66\%), Blog (57\%) - conforme ilustra a Figura 5. Entretanto, houve aqueles que se declararam em dúvida: Blog (29\%), Twitter (26\%), WhatsApp (19\%), Facebook (12\%). Por fim, aqueles que se mostraram favoráveis a compartilhar: Blog (14\%), WhatsApp (13\%), Twitter (7\%), Facebook (5\%). É interessante notar que, por mais que os participantes desconfiassem relativamente menos da notícia do Twitter do que da veiculada no WhatsApp, este último obteve mais intenção de compartilhamento.

Figura 5 - Motivação para o compartilhamento de fake news

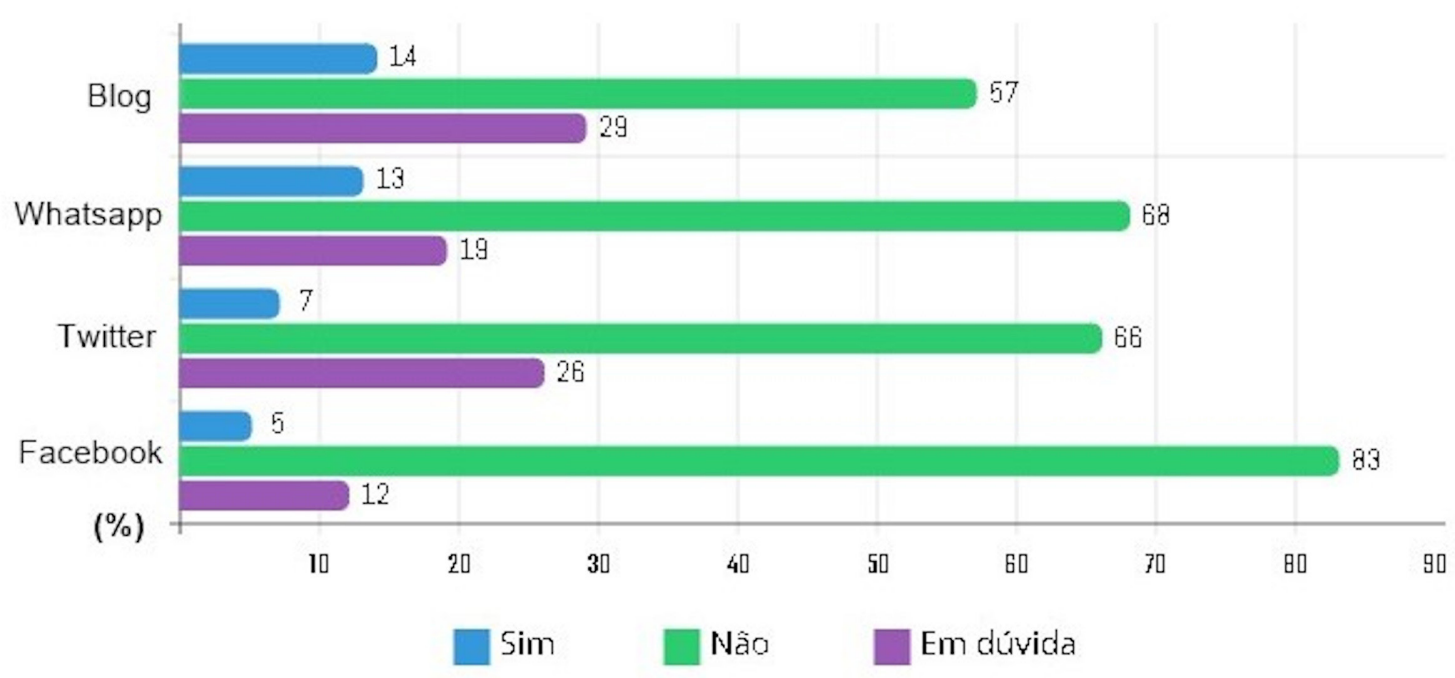

Fonte: elaborado pelos autores. 
Na sequência, os participantes foram questionados a respeito da seguinte situação: se fosse apresentada a mesma notícia a outra pessoa, ela consideraria ser fake news (Figura 6)? As maiores porcentagens foram atribuídas a 'em dúvida' e 'não', ou seja, a outra pessoa não seria capaz de saber que se tratava de fake news. As menores porcentagens concentraram-se na resposta 'sim', significando que as pessoas considerariam a notícia falsa. Esse resultado converge para a hipótese da terceira pessoa, segundo a qual, quando o participante é interrogado sobre uma questão negativa - nesse caso, o não reconhecimento de uma notícia como falsa -, interpreta-a como tendo mais peso sobre o outro do que sobre si.

Figura 6 - Possibilidade de outras pessoas considerarem a notícia falsa

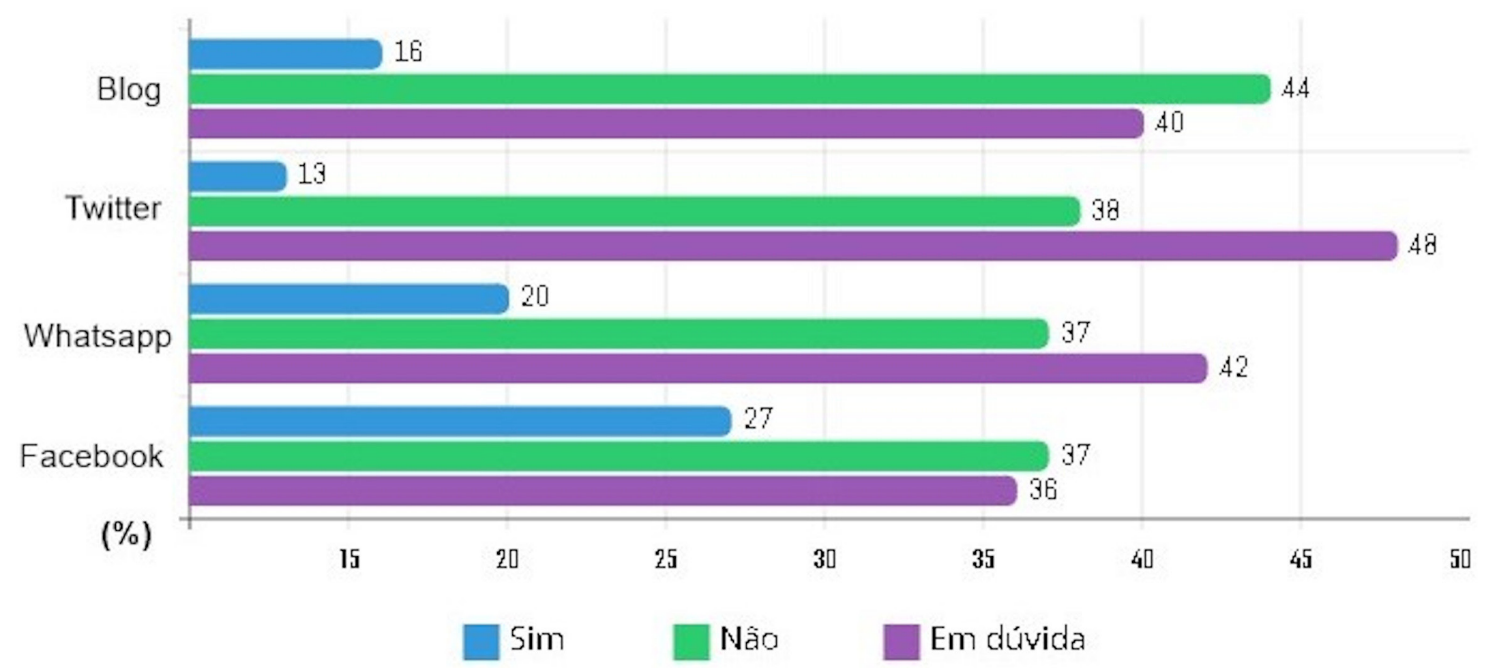

Fonte: elaborado pelos autores.

Outra análise realizada foi a respeito da renda familiar e sua relação com o reconhecimento de fake news (Figura 7). Nesse sentido, verificou-se que, quanto menor a renda familiar, maior a probabilidade de acreditar em fake news, consequentemente, quanto maior a renda familiar, menor a probabilidade de acreditar em notícias falsas.

Figura 7 - Identificação de fake news em relação à renda familiar

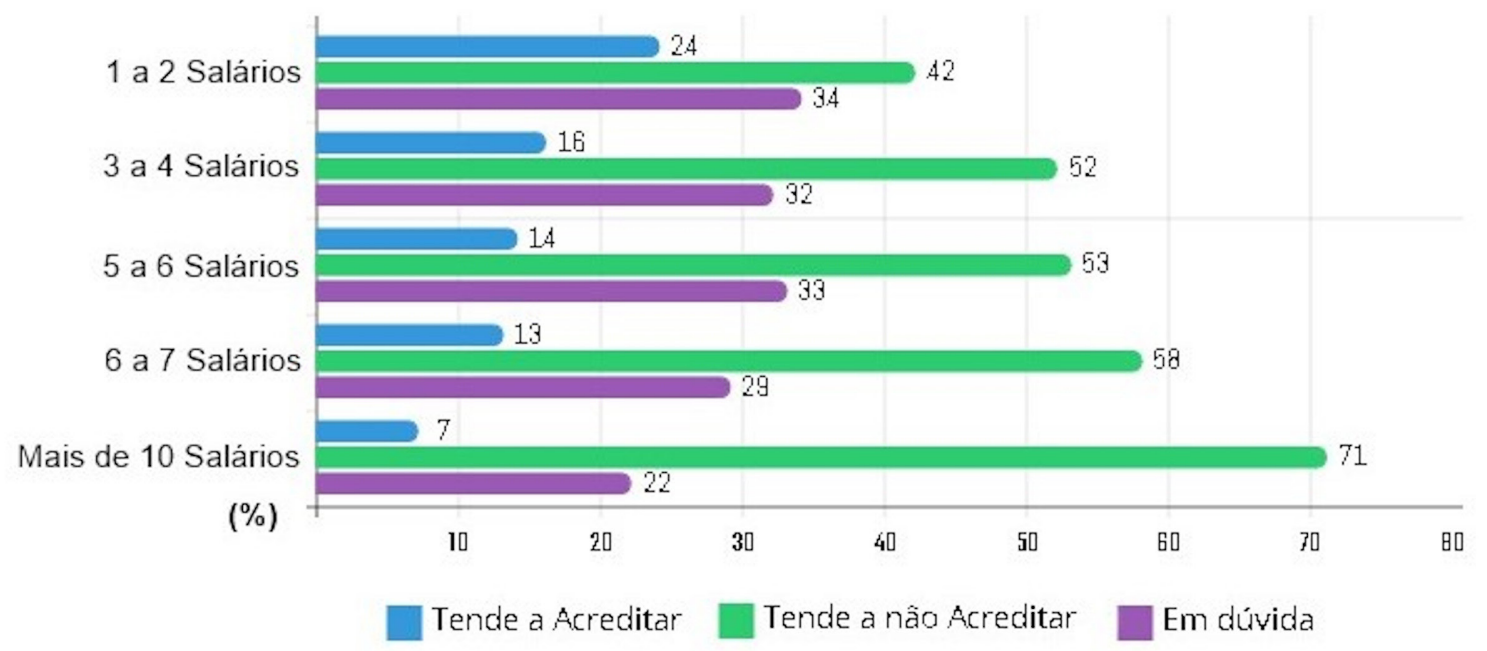

Fonte: elaborado pelos autores. 
Da mesma forma, foi realizada uma análise entre a identificação de fake news e a escolaridade (Figura 8). Foi possível constatar que, quanto menor a escolaridade, maiores são as chances de acreditar em notícias falsas, consequentemente, quanto maior o nível de escolaridade, menores são as chances de acreditar em fake news.

Figura 8 - Identificação de fake news em relação à escolaridade

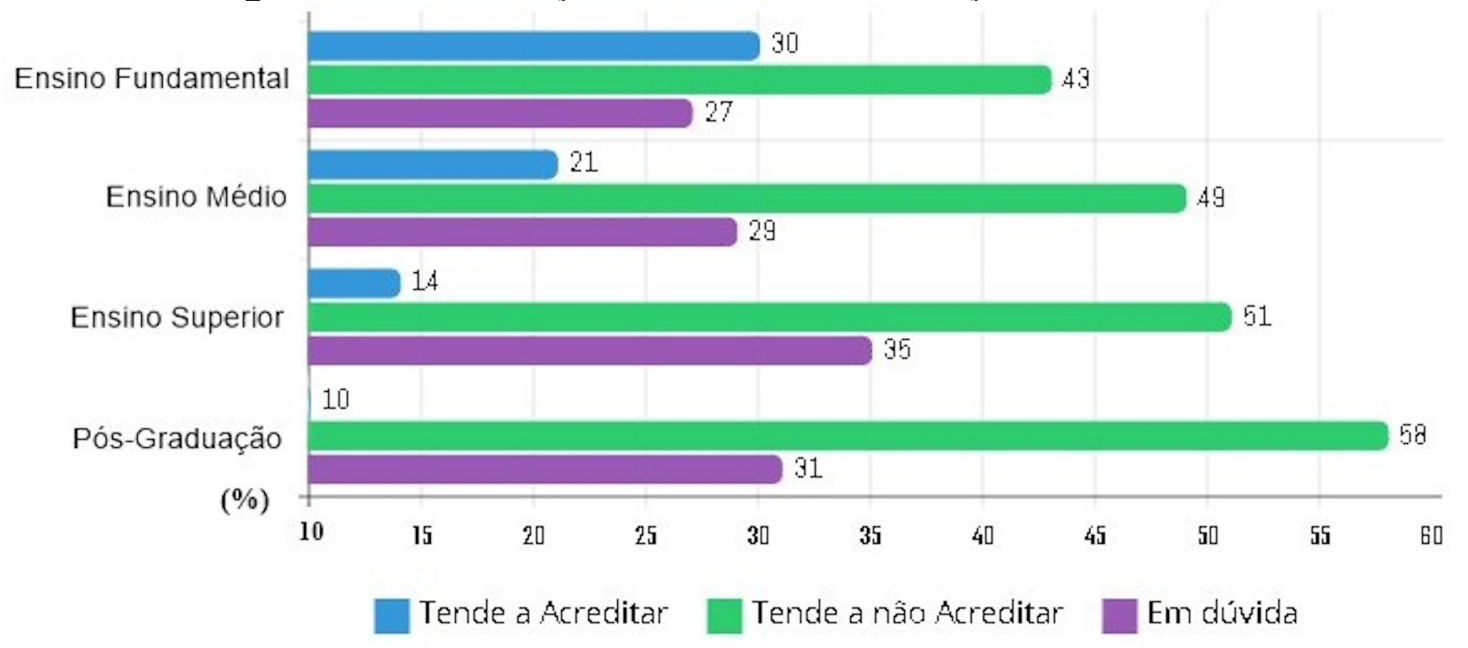

Fonte: elaborado pelos autores.

Outro questionamento levantado foi acerca de como os participantes faziam para saber se uma notícia era verdadeira ou falsa (Figura 9). A maioria indicou que julgava a veracidade de uma notícia por ser veiculada em sites confiáveis (55\%). Em seguida, vieram os que tinham como critério o teor científico (23\%), os próprios conhecimentos (20\%) e pessoas ou grupos que compartilhavam a notícia com eles (2\%).

'Teor científico' e 'meus conhecimentos' são respostas que, juntas, somam um número considerável de participantes (43\%). Note-se que a maioria das fake news apropriase de termos da comunidade científica (logos e ethos) para ter mais credibilidade e que os conhecimentos ou crenças pessoais também podem ser facilmente mobilizados para persuadir os leitores, principalmente por meio de pathos.

Figura 9 - Critério de embasamento para julgar a notícia como verídica

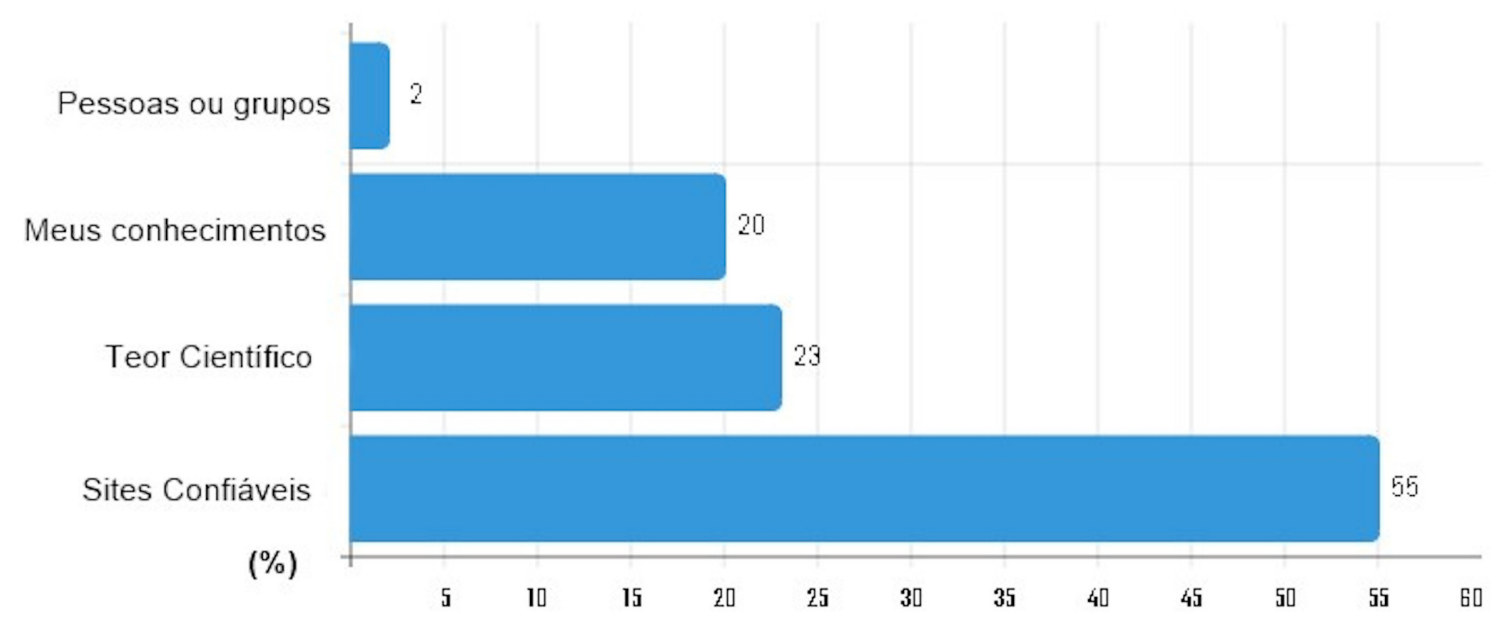

Fonte: elaborado pelos autores. 
Além das quatro fake news, foi inserida na pesquisa, para efeito de comparação, uma notícia verdadeira compartilhada via WhatsApp (Figura 10). A notícia em questão relatava que um remédio de hipertensão fora desenvolvido a partir de estudos com o veneno de uma serpente. A notícia falsa também veiculada por WhatsApp teve maior porcentagem de pessoas que a identificaram como falsa (49\%). Em seguida, houve os que ficaram em dúvida (37\%) e aqueles que a identificaram como verdadeira (14\%). Contudo, a notícia verdadeira, que deveria ter o maior percentual de pessoas que confirmassem sua veracidade, teve o maior índice de dúvida (44\%), seguido do índice dos que declaravam ser uma notícia falsa (37\%) e, por fim, aqueles que afirmaram ser verdadeira (19\%). Esse resultado abre precedentes para questionar se as pessoas realmente buscam sites confiáveis para verificar a procedência da notícia.

Figura 10 - Duas notícias, uma falsa e uma verdadeira, compartilhadas por WhatsApp

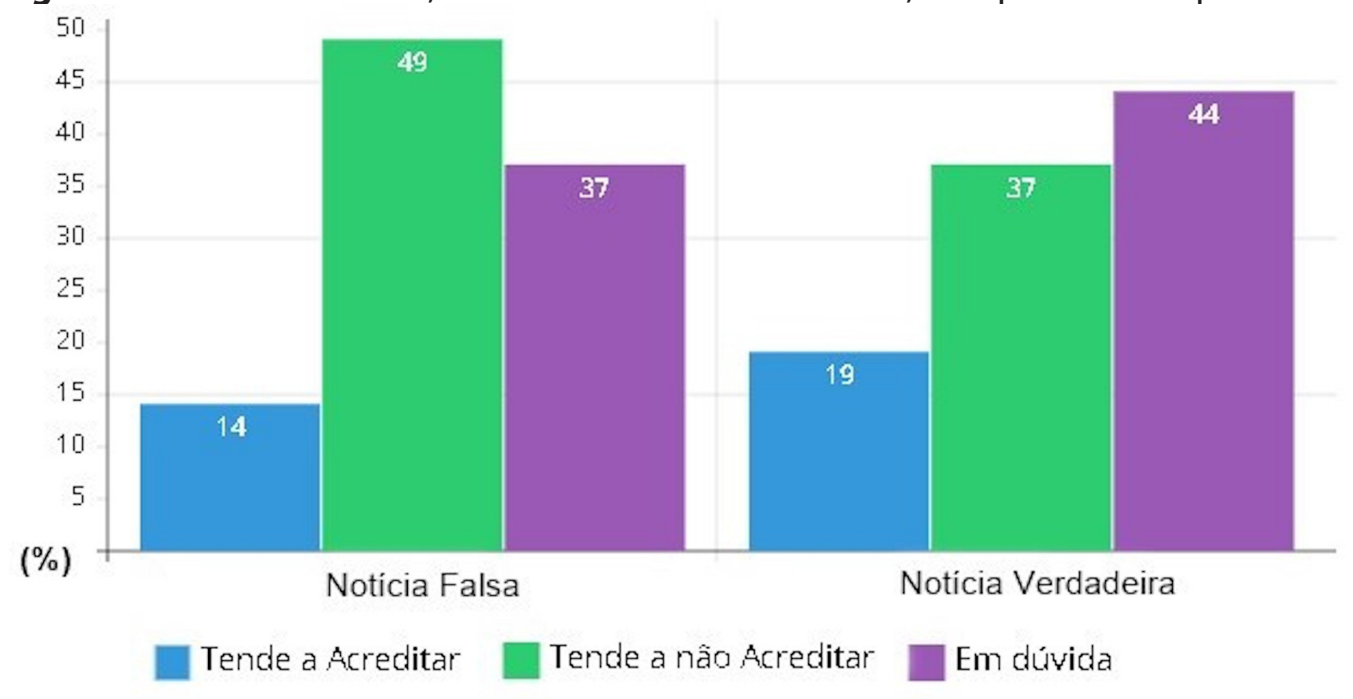

Fonte: elaborado pelos autores.

Os resultados sugerem que o uso do discurso persuasivo é imprescindível na eficiência de fake news científicas. Notícias falsas que apresentam mais pathos têm mais descrédito, ao passo que obtêm mais êxito as que melhor articulam os três pilares discursivos. Com relação à motivação de compartilhamento, foi interessante notar que, em relação ao Twitter, a mídia social WhatsApp obteve mais intenção de compartilhamento, mesmo tendo sido identificada por mais pessoas como potencial veiculadora de notícias falsas.

O efeito da terceira pessoa foi identificado frente à possibilidade de o outro ter mais chance de poder ser enganado pelas fake news. As pessoas com menor escolaridade e renda familiar mostraram-se mais suscetíveis às notícias falsas. As pessoas que dizem julgar uma notícia verídica por serem veiculadas em sites confiáveis são as mesmas que não o fazem, confiando nos seus próprios conhecimentos e no teor científico para considerar o que é ou não um fato.

\section{Considerações Finais}

Este artigo visou captar e interpretar, sob a luz da percepção e da persuasão, quais aspectos levam as pessoas a compartilhar notícias inverídicas, especialmente as de cunho científico. 
Constatou-se que as notícias falsas com mais chances de serem difundidas são aquelas dotadas de pathos, ethos e logos. Outro aspecto notado foi que, dependendo da plataforma em que é veiculada a notícia, as pessoas sentem-se mais inclinadas (ou não) a acreditar nela e compartilhá-la. Identificou-se que o uso de jargões científicos na estrutura de uma notícia falsa contribui para a validação de um discurso semelhante ao de especialistas. Evidenciouse que pessoas com menor renda e menor escolaridade estão mais suscetíveis às fake news. Verificou-se também a contradição sobre como os participantes julgavam a veracidade de uma informação. Eles afirmaram que o faziam por intermédio de sites confiáveis, entretanto, quando se depararam com uma notícia verdadeira, ficaram em dúvida e acabaram por julgála mais falsa que verdadeira.

Esses elementos identificados no estudo sugerem a necessidade dos letramentos midiático, informacional e científico para formar cidadãos mais autônomos e compromissados com fatos, e menos suscetíveis a emoções e crenças, conforme se constata neste momento da pós-verdade. Cabe ressaltar que esse atual desafio deve ser incorporado ao contexto escolar e, principalmente, à formação de professores para que possam contemplar essas novas demandas da sociedade conectada em rede. A distorção da realidade causada pelas fake news e a velocidade de difusão proporcionada pelas mídias sociais ameaçam configurações de poder, potencializando de forma engajada os contornos de uma realidade alternativa.

\section{Referências}

ARROIO, A. Is media literacy an urgent issue in education for all? Problems of Education in the $21^{\text {st }}$ Century, Siauliai, v. 75, n. 5, p. 416-418, 2017. Disponível em: http://oaji.net/ articles/2017/457-1509895265.pdf. Acesso em: 25 maio 2020.

BUENO, W. C. B. Jornalismo científico: revisitando o conceito. In: VICTOR, C.; CALDAS, G.; BORTOLIERO, S. (org.). Jornalismo científico e desenvolvimento sustentável. São Paulo: All Print, 2009. p. 157-78.

CACHAPUZ, A.; GIL-PEREZ, D.; CARVALHO, A. M. P.; PRAIA, J.; VILCHES, A. A necessária renovação do ensino das ciências. São Paulo: Cortez, 2005.

CUNHA, R. B. Alfabetização científica ou letramento científico?: interesses envolvidos nas interpretações da noção de scientific literacy. Revista Brasileira de Educação, Rio de Janeiro, v. 22, n. 68, p. 169-186, mar. 2017. DOI: https://doi.org/10.1590/s1413-24782017226809

DAVISON, W. P. The third-person effect in communication. Public Opinion Quarterly, Chicago, 47, n. 1, p. 1-15, 1983. DOI: https://doi.org/10.1086/268763

DICK, P. K. The shifting realities of Philip K. Dick: selected literary and philosophical writings. New York: Vintage, 1996.

GENESINI, S. A pós-verdade é uma notícia falsa. Revista USP, São Paulo, n. 116, p. 45-58, 29 maio 2018. Disponível em: http://www.revistas.usp.br/revusp/article/view/146577. Acesso em: 25 maio 2020.

GOUVÊA, L. H. M. Argumentação pela emoção: um caminho para persuadir. Rio de Janeiro: UFRJ, 2017.

HODGE, D. R.; GILLESPIE, D. F. Phrase completion scales: a better measurement approach than Likert scales? Journal of Social Service Research, Saint Louis, v. 33, n. 4, p. 1-12, 2007. DOI: https://doi. org/10.1300/J079v33n04_01tinyurl.com/y9knxgaz. Acesso em: 25 maio 2020. 
KANODE, C. F. Dumbing it down: mass media and science literacy in the USA. 2015. Thesis (Master of Fine Arts) - College of Arts \& Architecture, Montana State University, Bozeman, 2015. Disponível em: https://tinyurl.com/ycwrrs2x. Acesso em: 25 maio 2020.

LÜDKE, M.; ANDRÉ, M. E. D. Pesquisa em educação: abordagens qualitativas. São Paulo: EPU, 2007.

MEDRÁN, A. No reino da pós-verdade, a irrelevância é o castigo. UNO, São Paulo, n. 27, p. 33-35, 2017. Disponível em: https://tinyurl.com/y9knxgaz. Acesso em: 25 maio 2020.

MYERS, D. G.; DEWALL, C. N. Psicologia. 11. ed. Rio de Janeiro: EDEL, 2017.

OXFORD dictionary. Disponível em: https://www.oxforddictionaries.com/press/news/2016/12/11/ WOTY-16. Acesso em: 11 jan. 2019.

SANTOS, W. L. P. Educação científica na perspectiva de letramento como prática social: funções, princípios e desafios. Revista Brasileira de Educação, Rio de Janeiro, v. 12, n. 36, p. 474-492, 2007. DOI: https://doi.org/10.1590/S1413-24782007000300007

SOARES, M. Letramento: um tema em três gêneros. Belo Horizonte: Autêntica, 1998.

VOGT, C. Cultura científica: desafios. São Paulo: Edusp: Fapesp, 2006.

WILSON, C.; GRIZZLE, A.; MOORE, P.; DEZUANNI, M.; ASTHANA, S.; BANDA, F.; ONUMAH, C. Media and information literacy: policy and strategy guidelines. Paris: UNESCO, 2013. 